\title{
Interaction of Naegleria fowleri Trophozoites with Escherichia coli and MRSA by N-acetylglucosamine and Galactose
}

\author{
Dae-Hyun Son ${ }^{*}$ and Suk-Yul Jung ${ }^{\dagger, * *}$ \\ Department of Biomedical Laboratory Science, Molecular Diagnosis Research Institute, \\ Namseoul University, Cheonan-city, Choongnam 31020, Korea
}

\begin{abstract}
Naegleria fowleri is a free-living amoeba causing primary amoebic encephalitis. In this study, we analyzed how the $\mathrm{N}$-aceytlglucosamine (GlcNAc) and D-galactose affected the interaction between Naegleria fowleri and methicillin-resistant Staphylococcus aureus (MRSA) or Escherichia coli O157:H7, and the interaction with bacteria when monosaccharides were treated with $N$. fowleri for a longer pre-incubation time. When GlcNAc was treated with $N$. fowleri for $1 \mathrm{hr}$, the $E$. coli association was almost the same as that of the control not treated with GlcNAc until the concentration of GlcNAc was $25 \mathrm{mM}$. However, the E. coli association was reduced by approximately $91 \%$ with $100 \mathrm{mM}$ GlcNAc. E. coli invasion into $N$. fowleri showed statistical significance only in the group treated with $100 \mathrm{mM}$ GlcNAc. The interaction when treated with galactose showed a very different pattern in the $50 \mathrm{mM}$ galactose group than when treated with GlcNAc. In the MRSA interaction, a statistically significant decrease in association ( $76.3 \%$ by GlcNAc and $88.7 \%$ by galactose) and invasion (3.6\% by GlcNAc and $9.3 \%$ by galactose) was shown by the concentration of two $100 \mathrm{mM}$ monosaccharides. The group treated with monosaccharides at the same time showed almost no difference in all interactions from the group treated with monosaccharides at the same time. Taken together, it suggested that the effect of monosaccharides on the interaction of several Gram-negative or positive bacteria and the evidence that the interaction could be enhanced by longer pre-incubation time.
\end{abstract}

Key Words: Naegleria fowleri, N-aceytlglucosamine, D-galactose, Bacteria

Naegleria fowleri is a free-living amoeba that lives in rivers and lakes, and is a brain-eating amoeba known to cause primary amoebic encephalitis (PAME) in humans and experimental animals (Siddiqui et al., 2016; Jahangeer et al., 2020; Jung, 2021). The form of $N$. fowleri changes according to environmental requirements or infection if there are trophozoite, cyst and flagellate (Guzmán-Téllez et al., 2020). Among them, the trophozoite is active in eating bacteria or food because of the active pseudopodial move- ment (Marciano-Cabral and Cline, 1987). Although there were reports that $N$. fowleri could feed on microorganisms and survive, reports on the detailed mechanism are still insufficient (Walochnik et al., 2005; Visvesvara et al., 2007). However, in the presence of L-fucose, D-glucose, and Dmannose, it can bind to carbohydrate residues on the plasma membrane surface and allow bacteria to attach (CervantesSandoval., 2010; Jahangeer et al., 2020; Jung, 2021). Mannose is also well known in Acanthamoeba spp. as a free-

Received: November 5, 2021 / Revised: December 14, 2021 / Accepted: December 22, 2021

* Graduate student, ${ }^{* *}$ Professor.

${ }^{\dagger}$ Corresponding author: Suk-Yul Jung. Department of Biomedical Laboratory Science, Molecular Diagnosis Research Institute, Namseoul University, 91 Daehak-ro, Seonghwan-eup, Seobuk-gu, Cheonan-city, Choongnam 31020, Korea.

Tel: +82-41-580-2723, Fax:+82-41-580-2932, e-mail: syjung@nsu.ac.kr

(C) The Korean Society for Biomedical Laboratory Sciences. All rights reserved.

(c) This is an Open Access article distributed under the terms of the Creative Commons Attribution Non-Commercial License (http://creativecommons.org/licenses/by-nc/3.0/) which permits unrestricted non-commercial use, distribution, and reproduction in any medium, provided the original work is properly cited. 
living amoeba (Huth et al., 2017), and a recent study reported that mannose inhibited Methicillin-resistant Staphylococcus aureus (MRSA) association by nearly 168\% (Jung, 2021).

In this study, we analyzed how the $\mathrm{N}$-aceytlglucosamine (GlcNAc) and D-galactose (mentioned by galactose below) monosaccharides affected the interaction between $N$. fowleri trophozoites (mentioned by $N$. fowleri below) and MRSA or Escherichia coli O157:H7 (mentioned by E. coli below), and the interaction with bacteria when monosaccharides were treated with $N$. fowleri for a longer pre-incubation time.

$N$. fowleri (Carter NF69 strain, ATCC No. 30215) trophozoites were cultured aseptically at $37^{\circ} \mathrm{C}$ using Nelson's medium (Willaert, 1971). It was continuously subcultured so that about $95 \%$ of the trophozoites, in which a lot of pseudopods were observed, was maintained. In this study, two pathogenic bacteria were used. One was gram-negative $E$. coli (ATCC No. 43895) and the other was gram-positive MRSA (ATCC No. BAA-1769). A selective medium for bacteria was not used, but tryptic soy agar (TSA, MB cell, Korea) was used to propagate the bacteria at $37^{\circ} \mathrm{C}$. In addition, bacteria were confirmed once again through Gram staining (Lim et al., 1988). In order to accurately count the number of the bacteria, the bacteria were diluted with tryptic soy broth (TSB) and $0.85 \% \mathrm{NaCl}$ in advance so that the McFaland turbidity of 0.5 showed $0.5 \times 10^{3}$ to $1.5 \times 10^{6}$ colony forming units (cfu)/mL (Song and Jung, 2017). To investigate the effect of GlcNAc (Merck, Suwon, Korea) and galactose (Merck, Suwon, Korea) on the interaction between $N$. fowleri and bacteria, the concentrations of each monosaccharide were treated with 10,50, and $100 \mathrm{mM}$.

Analysis of the interaction between $N$. fowleri and $E$. coli or MRSA calculated how much the bacteria associated with $N$. fowleri, how much invasion into the $N$. fowleri and how long it survived within the $N$. fowleri. The experimental procedure was referenced by Jung et al. (2007) and several important procedures, e.g., pre-incubation time, the treatment of the detergent were changed. First, 10, 50 and $100 \mathrm{mM}$ monosaccharides were treated to $N$. fowleri $\left(5 \times 10^{4} /\right.$ well $)$ with phosphate-buffered saline (PBS) for $1 \mathrm{hr}$ in a 24-well cell culture plate at $37^{\circ} \mathrm{C}$. This reaction time was a preincubation time, which was doubled compared to the 30 minutes used in previous papers. Each bacterium $\left(2 \times 10^{5}\right.$ cfu/0.5 mL of PBS) were reacted with $N$. fowleri cultured in wells at room temperature (RT) for $1 \mathrm{hr}$. After washing wells 3 times with PBS, SDS ( $0.5 \%$ final concentration) was added for $1 \mathrm{hr}$ to completely dissolve $N$. fowleri instead of bacteria, and the number of bacteria was counted by plating on TSA. In this procedure, bacterial association percentages were calculated as follows: recovered bacteria (cfu)/total bacteria (cfu) $\times 100=\%$ bacteria associated with $N$. fowleri. Then, bacteria associated to $N$. fowleri can invade the $N$. fowleri. Therefore, it was analyzed how many bacteria invaded into $N$. fowleri. At first, gentamicin antibiotics $(100 \mu \mathrm{g}$ $/ \mathrm{mL}$, final concentration) was added for $45 \mathrm{~min}$ to remove the bacteria attached to or outside the $N$. fowleri cell wall. After washing wells 3 times with PBS, bacterial plating was done on TSA. The degree of bacterial invasion into the $N$. fowleri was calculated as follows: recovered bacteria (cfu)/ total bacteria $(\mathrm{cfu}) \times 100=$ percentage of invaded bacteria Bacteria invading into $N$. fowleri can either survive in the amoebae or are killed by enzymes in other organelles such as vacuoles. By adding PBS as the growth medium for $N$. fowleri, how much bacteria survived within $N$. fowleri for $24 \mathrm{hr}$ at $37^{\circ} \mathrm{C}$ was also analyzed. After the reaction time was over, all of the supernatant was removed, washed three times with PBS, and then the bacteria were plated on TSA. The degree of bacterial survival within the $N$. fowleri was calculated as follows: recovered bacteria (cfu)/total bacteria (cfu) $\times 100=$ percentage of survived bacteria. In all of the above processes, the monosaccharides were pre-reacted with $N$. fowleri, and then interactions with bacteria were analyzed. In addition, the interaction between $N$. fowleri and bacteria was analyzed by treating the monosaccharides while growing in the wells. For these reactions, association, invasion and survival were calculated using the formulas mentioned above.

Statistical significance was analyzed by comparing the control group untreated with monosaccharides and the experimental group treated with monosaccharides. Student twosample $t$-test was performed using the mean and standard deviation (SD). The statistically significant difference was $P<0.05$.

The most important point in this study was to analyze how GlcNAc and galactose other than mannose (Huth et al., 2017), which were key in previous studies, affect the 
interaction between $N$. fowleri and bacteria. Therefore, in this study, GlcNAc and galactose were pretreated with $N$. fowleri to saturate the $N$. fowleri cell wall with the above polysaccharide, and then, the interaction with bacteria was analyzed. Since it was confirmed that non-pathogenic bacteria had low interactions with free-living amoebae according to previous studies (Alsam et al., 2006), the interaction was analyzed using pathogenic bacteria such as E. coli or MRSA in this study. In addition, the effect of monosaccharide treatment on their interaction was analyzed when $N$. fowleri and bacteria were co-cultured. The interaction was to check whether bacteria were attached to $N$. fowleri and then invaded into $N$. fowleri and survived.

When GlcNAc was treated with $N$. fowleri for $1 \mathrm{hr}$, the $E$. coli association was almost the same as that of the control not treated with GlcNAc until the concentration of GlcNAc was $25 \mathrm{mM}$. Although not statistically significant, the $E$. coli association was reduced by about $11 \%$ when treated with $50 \mathrm{mM}$ GlcNAc. However, the E. coli association was reduced by approximately $91 \%$ with $100 \mathrm{mM}$ GlcNAc (Fig. 1, A1 and A2). In addition, when compared with the control group, there was a statistically significant difference from the group of the E. coli association treated with $100 \mathrm{mM}$ GlcNAc. E. coli invasion into $N$. fowleri showed statistical significance only in the group treated with $100 \mathrm{mM} \mathrm{GlcNAc}$, and the invasion was reduced by about $4.1 \%$ compared to the control group (Fig. 1, B1 and B2). One colony of E. coli survival within $N$. fowleri was found in the control group and the group treated with $10 \mathrm{mM}$ GlcNAc, but the survival rate was close to zero (Fig. 1, C1 and $\mathrm{C} 2$ ). The interaction when treated with galactose showed a very different pattern in the $50 \mathrm{mM}$ galactose group than when treated with GlcNAc (Fig. 1, D1, D2, E1, E2). In particular, in the group treated with $50 \mathrm{mM}$ galactose, about $169.7 \%$ of $E$. coli association and about $9 \%$ of $E$. coli invasion were reduced, respectively, and showed statistical significance compared to the control group. The interaction was gradually decreased with galactose than with GlcNAc according to the concentration of galactose. E. coli survival percentagewas close to zero even with galactose (Fig. 1, F1, F2).

MRSA, a Gram-positive bacterium, was analyzed for interaction like E. coli. (Fig. 2). Overall, when analyzing
Fig. 2, it was not confirmed that GlcNAc and galactose were gradually decreased according to the concentration. However, a statistically significant decrease in association ( $76.3 \%$ by GlcNAc and $88.7 \%$ by galactose) and invasion (3.6\% by GlcNAc and $9.3 \%$ by galactose) was shown by the concentration of two $100 \mathrm{mM}$ monosaccharides (Fig. 2, A1, A2, B1, B2, E1, E2). The survival rate within $N$. fowleri of MRSA was $0 \%$ without the effect of monosaccharides (Fig. 2, C1, C2, F1, F2).

All the above results were analyzed after pretreatment of monosaccharides with $N$. fowleri for $1 \mathrm{hr}$. The effect of monosaccharides was also analyzed if $N$. fowleri and bacteria were co-cultured described at groups marks with asterisks in Figure 1 and 2. The group treated with monosaccharides at the same time showed almost no difference in all interactions from the group treated with monosaccharides at the same time.

The $N$. fowleri trophozoite is a form that can eat bacteria or food well due to active psuedopodial movement (MarcianoCabral and Cline, 1987). According to previous studies, it is known that pathogenic bacteria interact with Acanthamoeba much more than non-pathogenic bacteria (Jung, 2011). Such an interaction can be established by a contact-dependent mechanism, and monosaccharides can serve as an intermediary for such interactions (Khan, 2003). In addition, there are reports that mannose plays a very important role in the interaction between Acanthamoeba spp. and bacteria, but there are still insufficient reports on which monosaccharides play a specific role in $N$. fowleri belonging to the same free-living amoeba. However, it has not yet been reported how much the interaction differs depending on whether the bacteria are gram-negative or positive. In the experimental procedure of this study, GlcNAc or galactose was added to $N$. fowleri for $1 \mathrm{hr}$, whereas in other studies, 30 minutes was mainly used. This was intended to enhance the interaction a little more.

The invasion percentages of bacteria entering the $N$. fowleri were confirmed by treatment with gentamicin antibiotics. In this study, it could be mistaken for percentages that were much smaller than the association experimental groups. For example, 9.1\% invasion in the control group was much smaller percentages than $176 \%$ association, but if 
A1

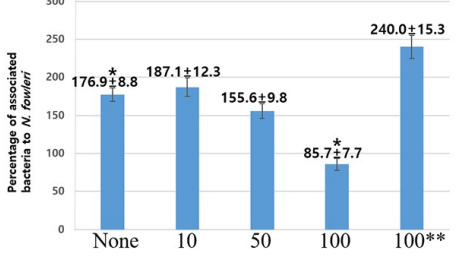

B1

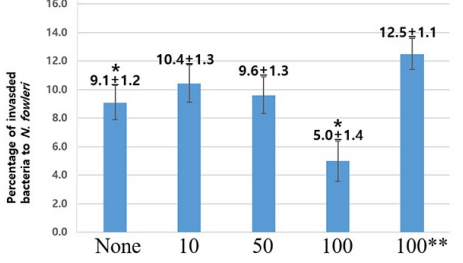

C1

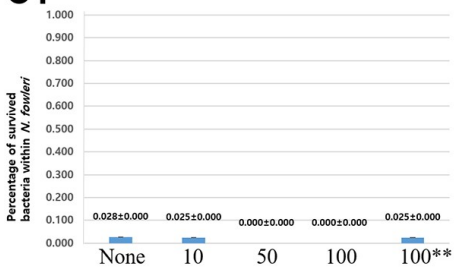

D1

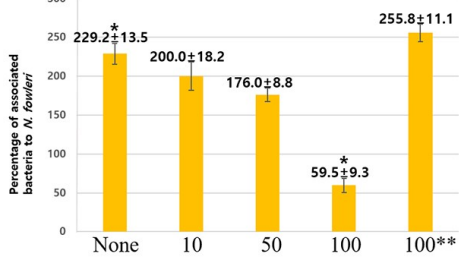

E1

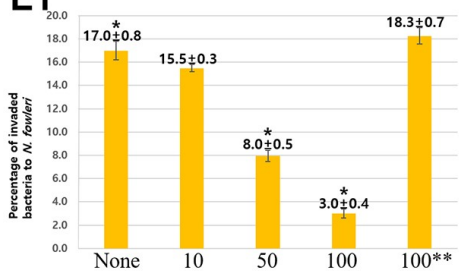

F1

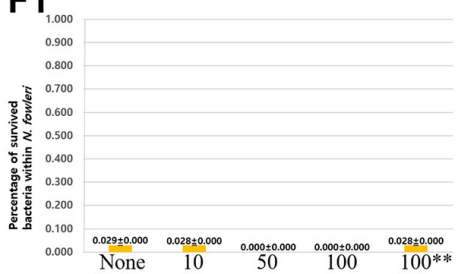

\section{A2}

\begin{tabular}{|l|c|c|c|c|c|}
\hline Treatment of GlcNAc & none & $10 \mathrm{mM}$ & $50 \mathrm{mM}$ & $100 \mathrm{mM}$ & $100 \mathrm{mM}^{* *}$ \\
\hline
\end{tabular} \begin{tabular}{|l|l|l|l|l|l|l|}
\hline Number of $N$. fowleri in a plate & 130000 & 155000 & 180000 & 105000 & 125000
\end{tabular}

\begin{tabular}{|l|l|l|l|l|l|l|}
\hline Bacterial colonies diluted 100-fold & 92 & 116 & 112 & 36 & 120 \\
\hline
\end{tabular}

\begin{tabular}{|l|l|l|l|l|l|}
\hline Total bacterial colonies grown & 230000 & 290000 & 280000 & 90000 & 300000 \\
\hline
\end{tabular}

B2

\begin{tabular}{|l|c|c|c|c|c|}
\hline Treatment of GlcNAc & none & $10 \mathrm{mM}$ & $50 \mathrm{mM}$ & $100 \mathrm{mM}$ & $100 \mathrm{mM}^{* * *}$ \\
\hline Number of $N$. fowleri in a plate & 110000 & 120000 & 130000 & 100000 & 100000 \\
\hline Bacterial colonies diluted 10-fold & 40 & 50 & 50 & 20 & 50 \\
\hline
\end{tabular}

\begin{tabular}{|l|l|l|l|l|l|}
\hline Bacterial colonies diluted 10-fold & 40 & 50 & 50 & 20 & 50 \\
\hline
\end{tabular}

\begin{tabular}{|l|l|l|l|l|l|}
\hline Total bacterial colonies grown & 10000 & 12500 & 12500 & 5000 & 12500 \\
\hline
\end{tabular}

\section{C2}

\begin{tabular}{|l|c|c|c|c|c|}
\hline Treatment of GlcNAc & none & $10 \mathrm{mM}$ & $50 \mathrm{mM}$ & $100 \mathrm{mM}$ & $100 \mathrm{mM}^{* *}$ \\
\hline Number of $N$. fowleri in a plate & 90000 & 100000 & 100000 & 95000 & 100000 \\
\hline Bacterial colonies diluted 0-fold & 1 & 1 & 0 & 0 & 1 \\
\hline Total bacterial colonies grown & 25 & 25 & 0 & 0 & 25 \\
\hline
\end{tabular}

D2

\begin{tabular}{|l|c|c|c|c|c|}
\hline Treatment of galactose & none & $10 \mathrm{mM}$ & $50 \mathrm{mM}$ & $100 \mathrm{mM}^{-100 \mathrm{mM}^{* *}}$ & 100 \\
\hline
\end{tabular} \begin{tabular}{|l|l|l|l|l|l|l|l|l|l|l|l} 
Number of $N$. fowleri in a plate & 120000 & 160000 & 125000 & 105000 & 130000
\end{tabular} \begin{tabular}{|l|l|l|l|l|l|}
\hline Bacterial colonies diluted 100-fold & 110 & 128 & 88 & 25 & 133 \\
\hline
\end{tabular}

\begin{tabular}{|l|l|l|l|l|l|}
\hline Total bacterial colonies grown & 275000 & 320000 & 220000 & 62500 & 332500
\end{tabular}

\section{E2}

\begin{tabular}{|l|c|c|r|r|r|}
\hline Treatment of galactose & none & $10 \mathrm{mM}$ & $50 \mathrm{mM}$ & $100 \mathrm{mM}^{100 \mathrm{mM}^{* *}}$ \\
\hline Number of $N$. fowleri in a plate & 100000 & 100000 & 110000 & 100000 & 100000 \\
\hline Bacterial colonies diluted 10-fold & 68 & 62 & 35 & 12 & 73 \\
\hline Total bacterial colonies grown & 17000 & 15500 & 8750 & 3000 & 18250 \\
\hline
\end{tabular}

F2

\begin{tabular}{|l|c|c|c|c|c|}
\hline Treatment of galactose & none & $10 \mathrm{mM}$ & $50 \mathrm{mM}$ & $100 \mathrm{mM}$ & $100 \mathrm{mM}^{* * *}$ \\
\hline Number of $N$. fowleri in a plate & 85000 & 89000 & 90000 & 90000 & 89000 \\
\hline Bacterial colonies diluted 0-fold & 1 & 1 & 0 & 0 & 1 \\
\hline Total bacterial colonies grown & 25 & 25 & 0 & 0 & 25 \\
\hline
\end{tabular}

Fig. 1. Interactions between $N$. fowleri and E. coli by GlcNAc and galactose. A1 and D1 showed association, B1 and E1 showed invasion, and $\mathrm{C} 1$ and F1 showed survival results. A2, B2, C2, D2, E2, and F2 represented CFU obtained for calculating the values of the graphs in the left panels. The number below the bar graph indicated the concentration of monosaccharides. An asterisk $(*)$ represented $P<0.005$. Other asterisks $(* *)$ showed the result of treating monosaccharides in co-cultured state of N. fowleri and E. coli.

only the invasion results were compared, the difference was more than double, so it could be judged that the difference between the invasion groups by GlcNAc or galactose was quite high. The parts marked with an asterisk in the experi- 
A1

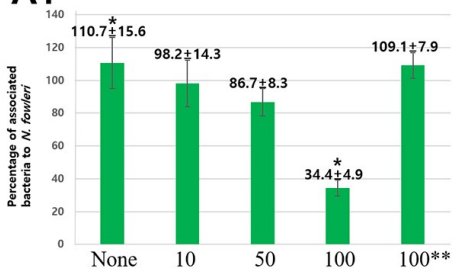

B1

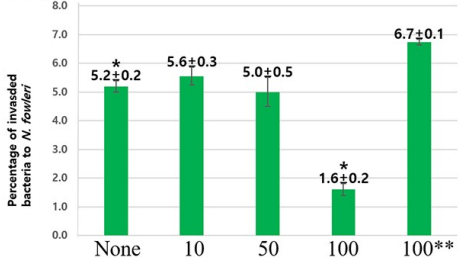

C1

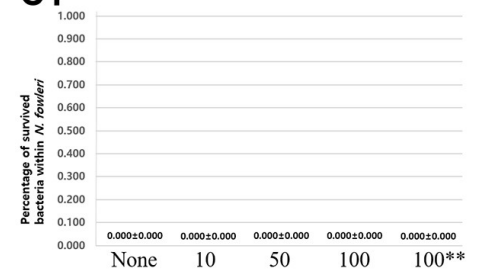

D1

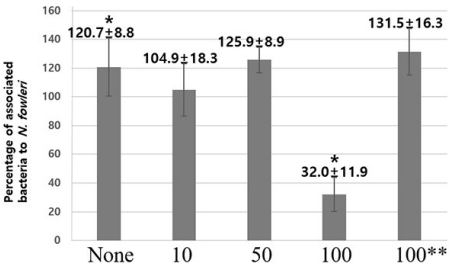

E1

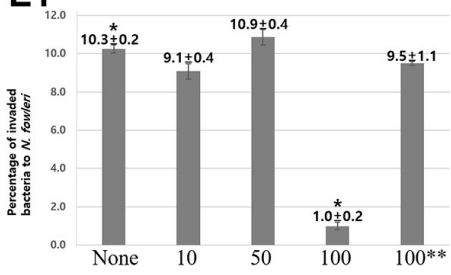

F1

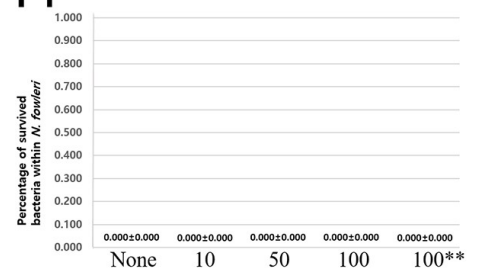

\section{A2}

\begin{tabular}{|l|c|c|c|c|c|} 
Treatment of GlcNAc & none & $10 \mathrm{mM}$ & $50 \mathrm{mM}$ & $100 \mathrm{mM}^{10}$ & $100 \mathrm{mM}^{* *}$
\end{tabular} \begin{tabular}{|l|l|l|l|l|l|l|}
\hline Number of $N$. fowleri in a plate & 140000 & 140000 & 150000 & 160000 & 165000
\end{tabular}

\begin{tabular}{|l|l|l|l|l|l|}
\hline Bacterial colonies diluted 100 -fold & 62 & 55 & 52 & 22 & 72 \\
\hline
\end{tabular}

\begin{tabular}{|l|l|l|l|l|l|}
\hline Total bacterial colonies grown & 155000 & 137500 & 130000 & 55000 & 180000 \\
\hline
\end{tabular}

B2

\begin{tabular}{|l|c|c|c|c|c|}
\hline Treatment of GlcNAc & none & $10 \mathrm{mM}$ & $50 \mathrm{mM}$ & $100 \mathrm{mM}$ & $100 \mathrm{mM}^{* *}$ \\
\hline Number of $N$. fowleri in a plate & 135000 & 135000 & 130000 & 125000 & 115000 \\
\hline Bacterial colonies diluted 10-fold & 28 & 30 & 26 & 8 & 31 \\
\hline Total bacterial colonies grown & 7000 & 7500 & 6500 & 2000 & 7750 \\
\hline
\end{tabular}

\section{C2}

\begin{tabular}{|l|c|c|c|c|c|}
\hline Treatment of GlcNAc & none & $10 \mathrm{mM}$ & $50 \mathrm{mM}$ & $100 \mathrm{mM}$ & $100 \mathrm{mM}^{* *}$ \\
\hline Number of $N$. fowleri in a plate & 80000 & 65000 & 87500 & 95000 & 84000 \\
\hline Bacterial colonies diluted 0-fold & 0 & 0 & 0 & 0 & 0 \\
\hline Total bacterial colonies grown & 0 & 0 & 0 & 0 & 0 \\
\hline
\end{tabular}

\section{D2}

\begin{tabular}{|l|c|c|c|c|c|}
\hline Treatment of galactose & none & $10 \mathrm{mM}$ & $50 \mathrm{mM}$ & $100 \mathrm{mM}$ & $100 \mathrm{mM}^{* *}$ \\
\hline Number of $N$. fowleri in a plate & 145000 & 162000 & 145000 & 125000 & 135000 \\
\hline Bacterial colonies diluted 100-fold & 70 & 68 & 73 & 16 & 71 \\
\hline Total bacterial colonies grown & 175000 & 170000 & 182500 & 40000 & 177500 \\
\hline
\end{tabular}

\section{E2}

\begin{tabular}{|l|c|c|c|c|c|}
\hline Treatment of galactose & none & $10 \mathrm{mM}$ & $50 \mathrm{mM}$ & $100 \mathrm{mM}$ & $100 \mathrm{mM}^{* *}$ \\
\hline Number of $N$. fowleri in a plate & 100000 & 110000 & 99000 & 100000 & 100000 \\
\hline Bacterial colonies diluted 10-fold & 41 & 40 & 43 & 4 & 38 \\
\hline Total bacterial colonies grown & 10250 & 10000 & 10750 & 1000 & 9500 \\
\hline
\end{tabular}

F2

\begin{tabular}{|l|c|c|c|c|c|}
\hline Treatment of galactose & none & $10 \mathrm{mM}$ & $50 \mathrm{mM}$ & $100 \mathrm{mM}$ & $100 \mathrm{mM}^{* *}$ \\
\hline Number of $N$. fowleri in a plate & 77000 & 82000 & 85000 & 79500 & 82000 \\
\hline Bacterial colonies diluted 0-fold & 0 & 0 & 0 & 0 & 0 \\
\hline Total bacterial colonies grown & 0 & 0 & 0 & 0 & 0 \\
\hline
\end{tabular}

Fig. 2. Interactions between $N$. fowleri and MRSA by GlcNAc and galactose. All sequences from A1 to F2 were the same as those described in Figure 1. An asterisk $\left(^{*}\right)$ represented $P<0.005$. Other asterisks $(* *)$ showed the result of treating monosaccharides in co-cultured state of N. fowleri and MRSA.

mental results explained that GlcNAc or galactose was treated in a cultured state of $N$. fowleri and bacteria. This meant that $N$. fowleri and bacteria competitively bound to
GlcNAc or galactose, since the interaction results were hardly different from those of the control group.

Through the results of this study, it was thought that the 
effect of monosaccharides on the interaction of several Gram-negative or positive bacteria and the evidence that the interaction could be enhanced by longer pre-incubation time.

\section{ACKNOWLEDGMENTS}

This work was supported by the National Research Foundation of Korea (NRF) grant funded by the Korea government (MSIT) (No. NRF-2020R1A2C1007952).

\section{CONFLICT OF INTEREST}

The authors have no conflicts of interest to disclose.

\section{REFERENCES}

Alsam S, Jeong SR, Sissons J, Dudley R, Kim KS, Khan NA. Escherichia coli interactions with Acanthamoeba: a symbiosis with environmental and clinical implications. J Med Microbiol. 2006. 55: 689-694.

Cervantes-Sandoval I, Serrano-Luna JJ, Pacheco-Yépez J, SilvaOlivares A, Tsutsumi V, Shibayama M. Differences between Naegleria fowleri and Naegleria gruberi in expression of mannose and fucose glycoconjugates. Parasitol Res. 2010. 106: 695-701.

Guzmán-Téllez P, Martínez-Valencia D, Silva-Olivares A, Del Ángel RM, Serrano-Luna J, Shibayama M. Naegleria fowleri and Naegleria gruberi 20S proteasome: identification and characterization. Eur J Cell Biol. 2020. 99: 151085.

Huth S, Reverey JF, Leippe M, Selhuber-Unkel C. Adhesion forces and mechanics in mannose-mediated Acanthamoeba interactions. PLoS One. 2017. 12: e0176207.

Jahangeer M, Mahmood Z, Munir N, Waraich UE, Tahir IM, Akram M, Ali Shah, SM, Zulfqar A, Zainab R. Naegleria fowleri: Sources of infection, pathophysiology, diagnosis, and management; a review. Clin Exp Pharmacol Physiol. 2020. 47: 199-212.
Jung SY, Matin A, Kim KS, Khan KA. The capsule plays an important role in Escherichia coli K1 interactions with Acanthamoeba. Int J Parasitol. 2007. 37: 417-423.

Jung SY. Effect of a mannose to the interactions between Naegleria fowleri and pathogenic bacteria. Biomed. 2021. 41: 623-629.

Khan NA. Pathogenesis of Acanthamoeba infections. Microb Pathog. 2003: 34: 277-285.

Lim KB, Boey LP, Khatijah M. Gram's-stained microscopy in the etiological diagnosis of Malassezia (Pityrosporon) folliculitis. Arch Dermatol. 1988. 124: 492.

Marciano-Cabral F, Cline M. Chemotaxis by Naegleria fowleri for bacteria. J Protozool. 1987. 34: 127-131.

Siddiqui R, Ali IKM, Cope JR, Khan NA. Biology and pathogenesis of Naegleria fowleri. Acta Trop. 2016. 164: 375-394.

Song KJ, Jung SY. Biocidal effects of chlorine dioxide on isolated and identified pathogens from nosocomial environment biochemical and technical convergence. J Digit Converg. 2017. 15: 339-344.

Visvesvara GS, Moura H, Schuster FL. Pathogenic and opportunistic free-living amoebae: Acanthamoeba spp., Balamuthia mandrillaris, Naegleria fowleri, and Sappinia diploidea. FEMS Immunol Med Microbiol. 2007. 50: 1-26.

Walochnik J, Müller KD, Aspöck H, Michel R. An endocytobiont harbouring Naegleria strain identified as N. clarki De Jonckheere,. 1994. Acta Protozool. 2005: 44: 301-310.

Willaert E. Isolement et culture in vitro des amibes de genre Naegleria. Ann Soc Belg Med Trop. 1971. 51: 701-708.

https://doi.org/10.15616/BSL.2021.27.4.323

Cite this article as: Son DH, Jung SY. Interaction of Naegleria fowleri Trophozoites with Escherichia coli and MRSA by N-acetylglucosamine and Galactose. Biomedical Science Letters. 2021. 27: 323-328. 